\title{
4 Poverty: A Catastrophic Alarm for Child Mental Health
}

Sampeet Mahanty, Asst. Scientific Officer, State Forensic Science Laboratory, Bhubaneswar, Odisha.email:sampeetmahanty@gmail.com

Manisha Mishra, Student Counsellor, Indian Institute of Technology (IIT), Bhubaneswar, Odisha. email:_manishamishra.psy@gmail.com

\begin{abstract}
Poverty by its growing magnitude has touched all most all the countries across the globe. The catastrophic impact of poverty not only disturbs an adult's social and psychological functioning but, it hinders a child's wellbeing and mental health. This paper aims to reveal the multifaceted effects of poverty on child mental health. The impact of various poverty variables on child mental health is reviewed. Prevalence in respect to world and India has been analysed.
\end{abstract}

Key words: Poverty, Catastrophic, Mental Health, Chronic Poverty and WHO

\section{Introduction}

Poverty has become a universal menace of modern civilization. The terrifying effect of poverty not only hinders the progress but, ceases the psycho-social development of the human being. Researches revealed that there is a close connection exists between poverty and mental health. Mental health is a state of psychological well-being; it is the "psychological state of someone who is functioning at a satisfactory level of emotional and behavioural adjustment". People living in chronic poverty tend to show a decreased level of mental health.

\section{Poverty}

Poverty is often defined as the lack of sufficient income to provide for the basic necessities of life, consistent with the norms of the society in which one lives (Canadian Mental Health Association, 2007). Poverty is associated with the undermining of a range of key human attributes, including health. The poor are exposed to greater personal and environmental health risks, are less well-nourished, have less information and are less able to access health care; they thus have a higher risk of illness and disability (World Health Organization). Poverty is a multidimensional phenomenon, encompassing inability to satisfy basic needs, lack of control over resources, lack of education and poor health. World Health Organization (1995) states, 'The world's most ruthless killer and the greatest cause of suffering on earth 
is extreme poverty.' This statement reveals the scenario of poverty as a variable adversely influencing health. The current prevalence of poverty casts its magnificent picture in terms of $36 \%$ of the population of the total population of the world. In India, the picture of poverty is also alarming in nature by comprising of approximately $22 \%$ of the total population.

The multifaceted effect of poverty not only hinders the development and maintenance of emotional, behavioural and social phenomenon of an individual but, adversely impacted the mental health. Hence the population below the age of 11 years (children) are very vulnerable to this.

\section{Adverse impact of poverty on child mental health}

The children experiencing poverty reveal that the experience of poverty in childhood can be highly damaging and the effects of poverty are both pervasive and disruptive. Social and emotional exclusion due to poverty in childhood leads to develop shame, sadness and the fear of difference and stigma within the child.

Financial and Material Deprivation: children are worried about the adequacy of income coming into their house and are afraid there would not be sufficient money for them and for their family's needs. children lacked basic childhood material, like toys, bicycles and games, and they also expressed concerns about being short of essentials and everyday items, like food, towels, bedding and clothing;

Social deprivation: poverty restricts children's chances to make and sustain social relationships and minimise their opportunities for shared social activities due to the costs of attending social events, inadequate and expensive transport provision.

School deprivation: children have fewer opportunities at school, largely through an inability to pay for resources such as study and exam materials, and restricted social opportunities through an inability to pay for school trips and other social activities. Inability to pay for compulsory items, such as uniforms, could also lead to conflict with teachers and decreased mental health. Approximately 121 millions of children are currently out of primary and secondary school worldwide. (The Borgen Project)

Feeling of Inferiority: a lack of the same material goods and clothes as their peers, and an inability to take part in the same social activities leads to children experience bullying and fear of stigma and social isolation. Inferiority leads to certain mental health conditions such as low self-esteem, depression and 
anxiety and psychologists may help people by talking through their feelings of inferiority and can directly address any early experiences such as deprivation, poverty etc. that contributed to the development of the feelings.

Family pressures: Children often tried to moderate their own needs in response to their parents' financial difficulties, wellbeing and working conditions which leads anxiety and stress.

Additional responsibilities: Children in low-income families are often taking on additional responsibilities in the home, including housework and caring responsibilities, or engaged in paid work themselves to ease financial pressures at home and to gain access to their own money, which levied extra pressure on them.

Poor Quality Residence and Homelessness: children have difficulties in sleeping; studying or playing at home resulted in poor health and wellbeing. Children experienced considerable anxiety about the quality of their temporary accommodation including a lack of privacy and no space for play. This affected their health, wellbeing and social participation.

\section{Mental Health}

Mental health is defined by the World Health Organization (WHO) as 'a state of well-being in which the individual realizes his or her own abilities can cope with the normal stresses of life, can work productively and fruitfully, and is able to make a contribution to his or her community'. Mental health is vital for individuals, families and communities, and is more than simply the absence of a mental disorder. It is being able to work and access to one's full potential, cope with day-to-day life stresses, be involved in the community, and live one's life in a free and satisfying way.

A person who has sound mental health has good emotional and social wellbeing and the capacity to cope with change and challenges. Mental health problems can affect one's feelings, thoughts and actions, and cause difficulties in everyday activities, whether at school, at work, or in relationships. Among various causes of mental health problems/illness, poverty (lower financial and material sources) plays a vital role in creating hindrance to mental health. Research findings state that due to poverty children get more affected in relation to mental health than adults. 


\section{Relationship between Poverty and Mental Health}

There is a close interaction exists between the variables of poverty and child mental health. Research studies found associations between symptoms of common mental health disorders such as depression and anxiety and poverty (Weich and Lewis, 1998a; Butterworth et al. 2009; Jenkins et al. 2008). However, poor quality of living conditions contributes to developing a lower mental health in children. For example, children living in low-quality housing, or fewer material and financial support cast a decreased level of mental health. Other effects of poverty which might lead to deterioration in mental well-being include low self-esteem, low self-efficacy and decreased motivation. Weich and Lewis (1998b) found that poverty and unemployment were both associated with the persistence of poor mental health, but not the onset of illness. Children of low incomes families are more likely to suffer from poor mental health and poverty effectively causing or contributing to poor mental health. It is also evident that both individual and neighbourhood deprivation increase the risk of poor general and mental health in children.

National Child Development Study data between 1958 and 2008 by the Centre for Longitudinal Studies, UK has shown that children from the lowest-income families are four times more likely (16\%) to display psychological problems than children from the richest families $(4 \%)$. This is further reinforced by evidence that shows children in poverty 'have more mental health problems than non-poor children.

Studies revealed that low socio-economic status is associated with a high prevalence of mood disorders (Dohrenwend et al, 1992). In addition, longitudinal research in Stirling County (Murphy et al, 1991) indicated that during the 1950s and 1960s the prevalence of depression was significantly and persistently higher in the low socio-economic status population than at other socio-economic status levels. Incidence of depression after the study began was also higher among those who were initially in the low socioeconomic status group, supporting the view that the stress of poverty may be causally related to depression. Deprivation causes physical health problems which greatly increase the risk of mental illness, particularly depression

Compared with the general population, people who attempt suicide belong more often to the social categories associated with social destabilisation and poverty (Department of Health, USA, 1999). Most surveys suggest an increased rate of mental health problems in children in families with low incomes compared to those in better-off households ( 1 in 6 , compared to 1 in 20). This difference is most exaggerated in boys, with double the risk. Attention deficit hyperactivity disorder (ADHD), bedwetting 
and self-harming behaviours show strong social patterns. Institute of Psychiatry in London found that poor general health and life events were related to emotional disorders. Conduct disorders were most closely associated with family variables (income, materials, housing etc.). According to international study children and adults from the lowest quintile (20 per cent) of household income are three times more likely to have common mental health problems (than those in the richest quintile) and nine times as likely to have psychotic disorders. Self-harm is more than three times as common in men and 2.5 times as common in women from the lowest 20 per cent of income compared with those from the highest 20 per cent.

The prevalence of mental health problems in children with poverty states an alarming view as follows:

$>$ Common mental disorders are about twice frequent among the poor then the higher socio-economic status people especially children.

$>$ People facing debts are more likely to suffer from common mental disorders.

$>$ Common mental disorders are also more prevalent for children living in poor and over crowed housing.

$>$ People with lowest socio-economic status (SES) have 8 times more relative risk for schizophrenia than those of the high SES

The expanding interaction and effect of poverty cease the development and nourishment of child mental health. Childhood is a period of germination of ideas, efficiency and self explorations. It needs a space where a child can experiment with things around him/her and learn the core values of life, which further leads to wellbeing and sound mental health. But unfortunately certain environmental variable like poverty hinders the ongoing process of learning of healthy behaviours by the child by its gigantic pressure. Keeping view on the catastrophic impact of poverty on individuals especially children, there should be certain strategies to provide a shield to protect the children from getting into poverty. Macro as well as micro-level planning in terms of financial and psycho-social mechanism should be developed to elevate poverty worldwide.

\section{References}

Butterworth, P., Rodgers, B and Windsor, TD (2009) Financial hardship, socio-economic position and depression: results from the PATH Through Life Survey. Social Science and Medicine 69: 229-237 
Canadian Institute for Health Information, Improving the Health of Canadians 2007-2008: Mental Health and Homelessness (Ottawa: CIHI, 2007)

Department of Health (1999a) National Confidential Inquiry into Suicide and Homicide by People with Mental Illness London: Department of Health.

Department of Health (1999b) Saving Lives: Our Healthier Nation. London: Stationery Office

Dohrenwend, Bruce P., Itzhak Levav, Patrick Shrout, Sharon Schwartz, Guedalia Naveh, Bruce Link, Andrew Skodol, and Ann Stueve. 1992. "Socioeconomic Status and Psychiatric Disorders: The Causation-Selection Issue.” Science 255:946-952

Government of India, (2001), Indian Planning Experience, A Statistical Profile, Planning Commission, New Delhi.

Horgan, G. (2007a). 'They are not looking at the cost of living': a study of income adequacy in Northern Ireland. Benefits

Jayaraman, R. and Lanjouw, P. (1999), The Evaluation of Poverty and Inequality in Indian Villages, The World Bank Research Observer Vol.14, No.1, February

Jenkins, R., D. Bhugra, P. Bebbington, T. Brugha, M. Farrell, J. Coid, T. Fryers, S. Weich, N. Singleton, and H. Meltzer. (2008) Debt, income and mental disorder in the general population. Psychological Medicine 38(10):1485-93.

Kempson, E. (1996). Life on a Low Income. York: Joseph Rowntree Foundation.

Murphy, J. M., Oliver, D. C., Monson, R. R., et al (1991) Depression and anxiety in relation to social status: a perspective epidemiological study. Archives of General Psychiatry, 48, 223-229

Power, A. (2007). City Survivors: Bringing up children in disadvantaged neighbourhoods, Bristol: Policy Press

Ridge, T. (2002). Childhood poverty and social exclusion: From a child's perspective, Bristol: Policy Press 
Ridge, T. and Millar, J. (2006). A fine balance: managing work and family life. Poverty

Ridge, T. (2006b). Childhood Poverty: A Barrier to Social Participation and Inclusion, in J. Davis, Tisdall, K., Prout, A. and Hill, M (ed.). Children, Young People and Social Inclusion: Participation for What?. Bristol: Policy Press.

UNICEF, The State of the World's Children (UNICEF, New York,2012).

Weich, S and Lewis, G. (1998a) Material standard of living, social class and the prevalence of common mental disorders. Journal of Epidemiology and Community Health 52, 8-14

Weich, S, and .G Lewis. (1998b) Poverty, unemployment, and common mental disorders: population based cohort study. British Medical Journal 317:115-19.

World Health Organization (1992) Tenth Revision of the International Classification of Diseases and Related Health Problems (ICD-10). Geneva: WHO.

World Health Organization (1995) Bridging the Gaps. Geneva: WHO.

World Bank Group (2004) Responding to Poverty: How to Move forward in Achieving the Millennium Development Goals? Washington, DC: World Bank Group.

\section{Web Resources:}

https://www.indexmundi.com/g/r.aspx? $\mathrm{v}=69$

http://www.worldbank.org/poverty/mission/rp1.htm

http://www.mapsofindia.com/my-india/society/poverty-in-india-and-its-causes

http://www.patient.co.uk/doctor/Poverty-and-Mental-Health.htm

http://www.headspace.org.au/media/183345/what\%20is\%20mental\%20health\%20factsheet18.pdf

http://www.nccp.org/publications/pub_687.html

https://borgenproject.org/global-dropout-rates-arent-improving/

https://www.childrenssociety.org.uk/sites/default/files/poor_mental_health_report.pdf

https://www.goodtherapy.org/blog/psychpedia/inferiority-complex 